\title{
Specialty Societies and Practice Standard Setting - Whose Job is it Anyway?
}

Can. J. Neurol. Sci. 2000; 27: 270

Specialty societies have no legally constituted role in the selfregulation of the medical profession in Canada but, nevertheless, are often the source of standards, guidelines or practice parameters that carry authority. This authority rests on the content expertise, prominence and inclusiveness of the specialty society, thereby gaining the voluntary compliance of its members and setting the bar for legally constituted regulators.

In Canada, provincial licensing authorities have been given responsibility for the regulation of "private practice" laboratories, where they are permitted to be established, including EEG and EMG labs. Nearly all these non-hospitalbased electrodiagnostic labs are in Alberta and Ontario. Predictably, the issue of their regulation has arisen most acutely in these two jurisdictions.

The College of Physicians and Surgeons of Alberta has licensed "private" EEG and EMG labs for several decades, established a program of recertification of these labs with regular reviews against standards in the mid-1980s and is now involved in accrediting hospital-based labs. The standards for these labs were established by local expert panels with external review and reference to standards published by American professional societies.

In the early 1990s it appeared to many observers that the lack of similar regulation of private labs in Ontario was leading to public risk. The College of Physicians and Surgeons of Ontario (CPSO) initially addressed facility standards for EEG labs and in 1995 heeded concerns from the EMG practice community about the proliferation of private EMG labs in the province and the rising cost of EMG services to the publicly funded health system. Although attempts were made to discredit these concerns as being motivated by the self-interest of an elite group of academic electromyographers, the argument that carried the day was that the CPSO had an obligation to ensure that infection control and electrical safety standards were met and that minimum qualifications for technical and professional staff were established. A multiple-stakeholder task force was established to develop a set of facility standards and clinical practice guidelines which it is anticipated the CPSO will adopt shortly.

With practice standards in place or about to be adopted by the provincial licensing authorities in the two jurisdictions in which private EMG labs are an issue, why has the EMG Section of the Canadian Society of Clinical Neurophysiologists (CSCN) gotten its oar in the water now ${ }^{1}$ What business is it of theirs anyway?

By publishing ratified Minimum Standards for EMG in
Canada, the CSCN is, in my view, staking a legitimate claim of authority over the content of self-regulatory standards that may be applied by the provincial colleges and providing a template (based on a national consensus) for jurisdictions currently without regulatory standards. The society is not a small elite, reflecting a narrow bias, but rather is an organization that is broadly representative of neurologists and physiatrists doing electromyography across the country. What better group to set the bar? What better source of direction for the provincial licensing authorities?

Are the minimum standards advanced by the CSCN too "minimal"? The CPSO task group has developed detailed clinical practice guidelines in an attempt to establish some standards around indications. There is, however, almost no Class I information upon which to base such guidelines and accordingly they remain heavily "eminence-based". The Ontario task group has wisely disclaimed any attempt to consider their clinical practice guidelines to be prescriptive and has emphasized the importance of their utility, based on the clinical judgment of the individual electromyographer. Anything more prescriptive cannot be justified by evidence. High level evidence will accumulate in the future however, and it is critically important that published standards are regularly reviewed and updated.

Practice standards established by a respected national specialist society are a threat to some. Practitioners who have not challenged the CSCN or American EMG exams and who lack confidence that their own practice would meet the standards of their peers, may object that EMG standards are a matter for their provincial colleges, not the CSCN. But standards are also a source of protection. They protect electromyographers who can point to their own compliance to standards if challenged and, more importantly, they protect the public. Ensuring the public credibility of its discipline is surely the job of a specialty society.

M.G. Elleker

Edmonton, Alberta

\section{REFERENCE}

1. Bolton CF, Benstead TJ, Grand'Maison F, Tardif GS, Weston LE. Minimum standards for electromyography in Canada. Can $\mathbf{J}$ Neurol Sci (this issue). 